\title{
Monosaccharide composition of Herniaria glabra L. and Herniaria polygama J.Gay
}

\author{
Solomita KozachoK ${ }^{1 \star}$, Svitlana Marchyshyn ${ }^{1}$, Andriy OstapchuK ${ }^{2}$, LiUdmyla Zavyalova ${ }^{3}$ \\ ${ }^{1}$ Department of Pharmacognosy with Medical Botany, Pharmaceutical Faculty, I Horbachevsky Ternopil State Medical University, \\ Ruska 36, 46001 Ternopil, Ukraine \\ ${ }_{2}^{2}$ Department of Microbiology, Virology and Biotechnology, Odesa I.I. Mechnikov National University, Dvoryanska 2, 65082 Odessa, Ukraine \\ ${ }^{3}$ Department Of Systematics And Floristics Of Vascular Plants, M.G. Kholodny Institute of Botany, NAS of Ukraine, 01004 Kyiv, Ukraine
}

\section{ARTICLE INFO \\ Received 09 August 2016 \\ Accepted 29 August 2016}

\section{Keywords:}

Herniaria glabra L.,

Herniaria polygama J.Gay, monosaccharides, GS-MS

\begin{abstract}
The plants from Herniaria genus (Caryophyllaceae family) are mainly applied as diuretic agents for the treatment of kidney and gall-stones, gouts, urinary tract infections, hypertension and diabetes. The most widely spread species in Europe is Herniaria glabra L. (HG).Herniaria polygama J.Gay (HP) is found growing from Eastern Europe to Asia. Surprisingly, no work has been reported on the analysis of primary metabolites of HP yet and there is only a limited data on HG. The aim of our study was to establish the monosaccharide composition after a complete hydrolysis and in a free state in the entire herbs of HG and HP harvested in the western and central parts of Ukraine. The carbohydrates were separated by gas chromatography-mass spectrometry after conversion into volatile derivatives as aldononitrile acetate. As a result, the monosaccharide composition after a total hydrolysis was established with the contribution of the following components: D-rhamnose, D-arabinose, D-fucose, D-xylose, D-manose, D-glucose, D-galactose, D-pinitol, myo-inisitol, D-mannitol, D-dulcitol. In a free state it was detected: $\mathrm{D}$-fructose, $\mathrm{D}$-glucose, $\mathrm{D}$-galactose, $\mathrm{D}$-pinitol, myo-inisitol, D-mannitol and D-saccharose. The following monosaccharides were found in the most abundant quantities in HG and HP respectively: glucose was determined as the major component -33.40 and $22.80 \mathrm{mg} / \mathrm{g}$, the second dominant sugar was pinitol -16.80 and $18.07 \mathrm{mg} / \mathrm{g}$, followed by galactose $-13.88 \mathrm{mg} / \mathrm{g}$ in HG and arabinose $-8.13 \mathrm{mg} / \mathrm{g}$ in HP. Sugars were determined in these plant species for the first time and this finding shed new light on their pharmacological application.
\end{abstract}

\section{INTRODUCTION}

The Herniaria L. genus from Caryophyllaceae family is the major group among the flowering plants. Plants of this genus growth in Europe, South America (Ande), central and western Asia and Africa. The most spread species in Europe is Herniaria glabra L. (HG). The herb is officially present in the Pharmacopeias of Poland, Czech Republic, Austria, Hungary and Balkans area. In traditional medicine HG is used for the treatment of kidney and bladder stones, gouts, urinary bladder infections, renal disease, diabetes, hernias, hypertension, cardiac decompensation, as well as rheumatism, and was externally applied as an antiseptic and skin emollient. Diuretic, spasmolytic, antihypertensive

\footnotetext{
* Corresponding author

e-mail: solomiia.kozachok@gmail.com
}

( $80 \%$ methanolic extract of HG) and hypoglycemic activity (aqueous extract of $\mathrm{HG}$ ) was proven by the in vivo experiments $[1,6]$. The main groups of biologically active substances of HG are triterpenoid saponins, flavonoids and phenyl carboxylic acids and there is a limited number of data on the primary metabolites from HG [6].

Another species - Herniaria polygama J.Gay (HP) - is spread between the Eastern Europe and the European parts of Russia, Western Siberia, Kazakhstan, Pakistan reaching China. HP is widespread in the territories of Ukraine and can be perceived as an alternative source for the officinal one - HG [3]. The studies on the chemical constituents from HP (coumarins and flavonoids) are scarce and there is no data on saponins and primary metabolites content available in the scientific literature [1]. 
The aim of our study was to establish the monosaccharide composition both in a free state and after a complete hydrolysis in the entire herbs of HG and HP harvested in the western and central parts of Ukraine.

\section{MATERIALS AND METHODS}

\section{Plant materials}

The entire plants of HG and HP were harvested from wild plots in the western (Ternopil region, Ditkivtsi village - HG) and the central (Kiev region, Kyiv-Sviatoshynskyi district, Dmytrivka village - HP) parts of Ukraine during the flowering stage on June-July, 2014. The collected specimens were identified by dr. Liudmyla Zavialova.

\section{Chemicals and standards}

All reagents were of analytical grade ( $>95 \%$ purity). Standard reagents including D-mannose (Man), L-rhamnose (Rha), D-ribose (Rib), D-galactose (Gala), D-xylose (Xyl), D-arabinose (Ara), D-fucose (Fuc), D-glucose (Glc), D-fructose (Frc), D-saccharose (Sac), D-sorbitol were purchased from Sigma-Aldrich, USA. The water used in the studies was produced by MilliQ Gradient water deionizaton system (Millipore, Bedford, MA, USA). Methanol, trifluoroacetic acid, hydroxylamine hydrochloride, pyridine, dichloroethane, hydrochloride acid, heptanes, ethyl acetate were purchased from Sigma-Aldrich, USA.

\section{Chromatographic condition}

The chromatographic separation and identification of carbohydrates was performed on the gas chromatographymass spectrometry (GS/MS) system model 6890N/5973inert (Agilent Technologies) using a capillary column HP-5ms $(30 \mathrm{~m} \times 0.25 \mathrm{~mm} \times 0.25 \mu \mathrm{m})$. For the determination of acetylated aldononitriles the oven temperature was initially at $160^{\circ} \mathrm{C}$, held for $8 \mathrm{~min}$, then ramped at the rate of $5^{\circ} \mathrm{C} / \mathrm{min}$ to $240^{\circ} \mathrm{C}$ and finally held at this temperature for $6 \mathrm{~min}$. Injections were performed in the split mode. The detection was held in the SCAN mode in the range of $(38-400 \mathrm{~m} / \mathrm{z})$. Identification was performed by the comparing of the retention time of the mixture of monosaccharides and $\mathrm{Sac}$ standards and mass library NIST 02 . The quantification analysis was done by the adding into the sample an internal standard of sorbitol [2].

\section{Procedure}

The free monosaccharides. To the powdered plant materials $80 \%$ ethanol solution with an internal standard (sorbitol) were added. The extraction was held in the ultrasonic water bath at $80^{\circ} \mathrm{C}$ for 4 hours. Extract was evaporated to dryness.

The monosaccharides after hydrolysis. To the powdered plant materials, $2 \mathrm{M}$ of trifluoroacetic acid was added. Hydrolysis was done at $100^{\circ} \mathrm{C}$ for 6 hours. After filtration with the filter paper the hydrolysate was evaporated to dryness.

\section{Derivatisation}

Herein $0,3 \mathrm{ml}$ of a derivatization reagents $(32 \mathrm{mg} / \mathrm{ml}$ of hydroxylamine hydrochloride in the mixture of pyridine/ methanol $(4: 1 \mathrm{v} / \mathrm{v}))$ was added to the dried hydrolysate. Samples were incubated in a preheated water bath shaker at $75^{\circ} \mathrm{C}$ for $25 \mathrm{~min}$. After the incubation, $1.0 \mathrm{~mL}$ of acetic anhydride was subsequently added to the samples and incubated at $75^{\circ} \mathrm{C}$ for $25 \mathrm{~min} .2 \mathrm{ml}$ of dichloromethane was added to the mixture, the excess of the derivatization reagents was removed by the double extraction with $1 \mathrm{M}$ hydrochloride acid solutions and water. Dichloromethane layer was dried and dissolved into $300 \mu \mathrm{L}$ of the mixture of heptane/ethyl acetate $(1: 1, \mathrm{v} / \mathrm{v})$.

The amount of carbohydrates in $\mathrm{mg} / \mathrm{g}$ was calculated according to the following equation:

$$
\mathrm{X}=\frac{\text { Sx } \times \text { Minst } \times 1000}{\text { Minst } \times m}
$$

where: Sx is a peak area of each monosaccharides or disaccharide, Minst is a mass of the internal standard, Sinst is a peak area of the internal standard, $\mathrm{m}$ is a mass of a plant material.

\section{RESULTS AND DISCUSSION}

The GS-MS-analysis resulted in the identification of 11 monosaccharides. Rha, Ara, Fuc, Xyl, Man, Glc, Gala, D-pinitol, myo-inisitol, D-mannitol, and dulcitol were detected in the entire herbs of HG and HP after acidic hydrolysis and subsequently derivatized into acetylated aldononitriles. Additionally, free carbohydrates were extracted from the water-methanol solution of the studied objects: Frc, Sac, Glc, Gala, D-pinitol, myo-inisitol, D-mannitol. The outcomes of chromatographic analyzes of HG and HP are presented in Figure 1 and Figure 2.

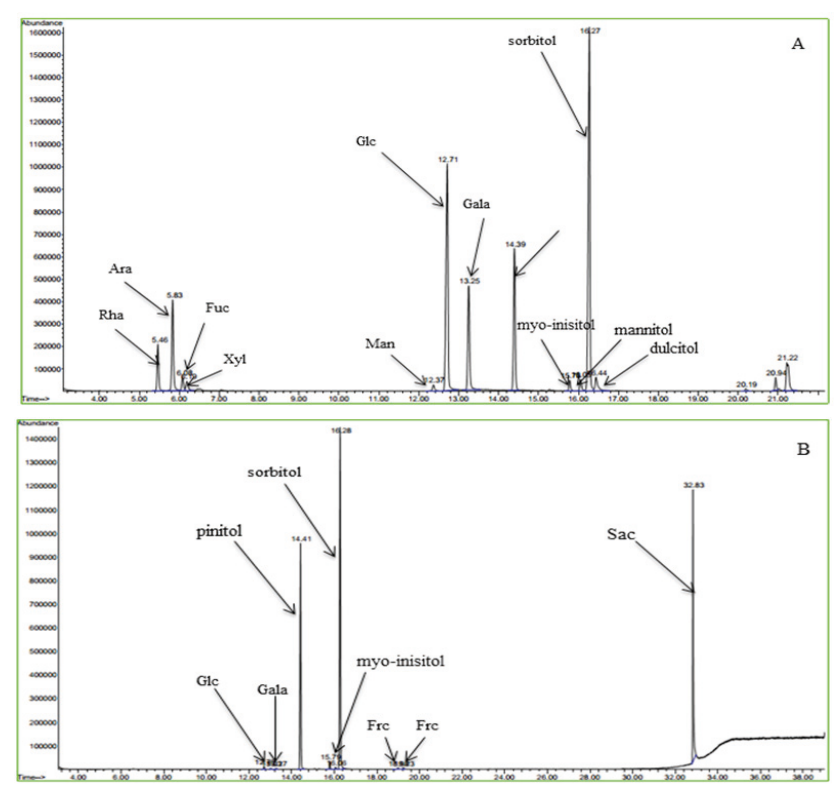

Figure 1. GC-MS chromatograms of monosaccharides (A) and free carbohydrates (B) of Herniaria glabra 


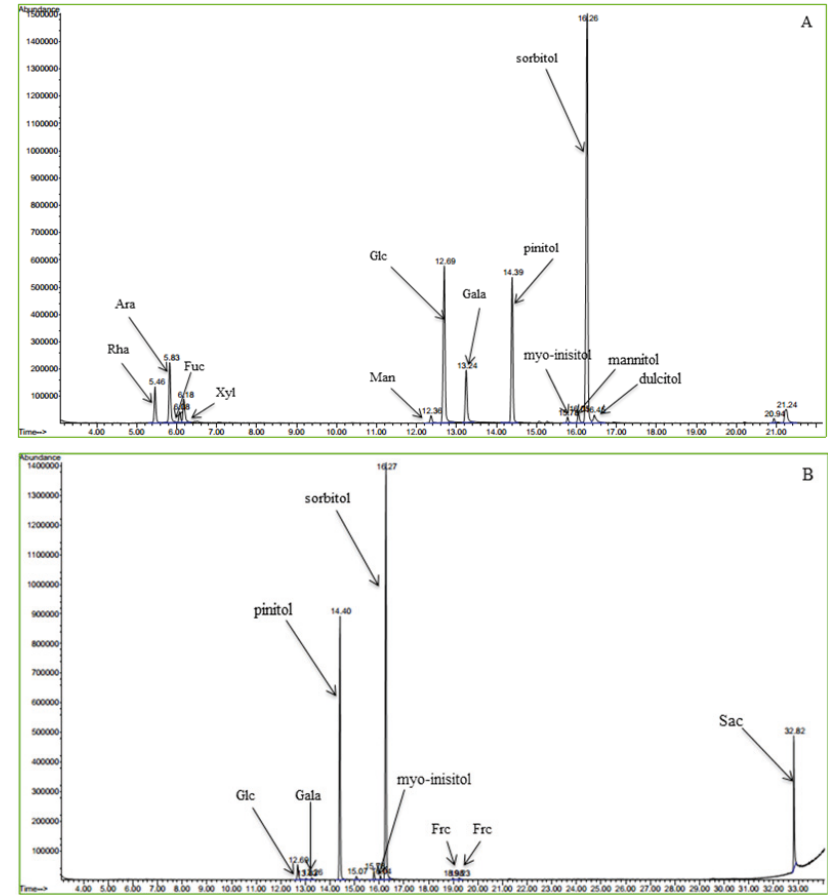

Figure 2. GC-MS chromatograms of monosaccharides (A) and free carbohydrates (B) of Herniaria polygama

The quantity content of carbohydrates was calculated in reference to the internal standard - sorbitol in $\mathrm{mg} / \mathrm{g}$ and presented in the Table 1. The following monosaccharides were found in the most abundant quantities in HG and HP respectively: Glc was determined as the major component - 33.40 and $22.80 \mathrm{mg} / \mathrm{g}$, the second dominant sugar was pinitol -16.80 and $18.07 \mathrm{mg} / \mathrm{g}$, followed by Gala -13.88 $\mathrm{mg} / \mathrm{g}$ in $\mathrm{HG}$ and $\mathrm{Ara}-8.13 \mathrm{mg} / \mathrm{g}$ in HP.

Table 1. Quantity content of monosacchirides after complete hydrolysis and free carbohydrates (mg/g) of the herb of Herniaria glabra and Herniaria polygama

\begin{tabular}{|c|c|c|c|c|c|c|c|}
\hline \multirow[t]{2}{*}{ No } & \multirow{2}{*}{$\begin{array}{c}\text { Name of } \\
\text { carbohydrates }\end{array}$} & \multirow{2}{*}{$\begin{array}{l}\mathrm{RT}, \\
\mathrm{min}\end{array}$} & \multicolumn{2}{|c|}{$\begin{array}{c}\text { Monosaccharides, } \\
\mathrm{mg} / \mathrm{g}\end{array}$} & \multirow{2}{*}{$\begin{array}{l}\mathrm{RT}, \\
\mathrm{min}\end{array}$} & \multicolumn{2}{|c|}{$\begin{array}{c}\text { Free } \\
\text { carbohydrates, } \\
\mathrm{mg} / \mathrm{g}\end{array}$} \\
\hline & & & HG & HP & & HG & HP \\
\hline 1 & D-Rhamnose & 5.46 & 5.36 & 4.38 & 5.46 & - & - \\
\hline 2 & D-Arabinose & 5.83 & 11.51 & 8.13 & 5.83 & - & - \\
\hline 3 & D-Fucose & 6.08 & 1.79 & 1.45 & 6.08 & - & - \\
\hline 4 & D-Xylose & 6,17 & 1.48 & 3.67 & 6.17 & - & - \\
\hline 5 & D-Manose & 12.36 & 0.99 & 1.22 & 12.36 & - & - \\
\hline 6 & D-Glucose & 12.69 & 33.40 & 22.80 & 12.69 & 0.26 & 1.31 \\
\hline 7 & D-Galactose & 13.24 & 13.88 & 7.64 & 13.26 & 0.15 & 0.20 \\
\hline 8 & (+)-Pinitol & 14.39 & 16.80 & 18.07 & 14.39 & 16.76 & 17.60 \\
\hline 9 & Myo-inositol & 15.78 & 1.28 & 0.73 & 15.78 & 0.63 & 0.59 \\
\hline 10 & D-Mannitol & 16.05 & 1.60 & 1.42 & 16.05 & 0.19 & 0.28 \\
\hline 11 & D-Sorbitol & 16.27 & \multicolumn{5}{|c|}{ inner standard } \\
\hline 12 & $\begin{array}{l}\text { D-Dulcitol } \\
\text { (Galactiol) }\end{array}$ & 16.45 & 2.84 & 2.05 & 16.45 & - & - \\
\hline 13 & D-Fructose & $\begin{array}{l}18.98 \\
19.23 \\
\end{array}$ & - & - & $\begin{array}{l}18.98 \\
19.23\end{array}$ & $\begin{array}{l}0.12 \\
0.15 \\
\end{array}$ & $\begin{array}{l}0.14 \\
0.17 \\
\end{array}$ \\
\hline 14 & D-Saccharose & 32.83 & - & - & 32.83 & 15.53 & 6.13 \\
\hline
\end{tabular}

Due to the reference data, highest quantity of monosaccharides in the plants from Herniaria genus are linked with sapogenin (medicagenic acids derivatives) and flavonoid aglycones [4]. Thus in the studied objects, there is the residue of Glu and Gala and absent of Rha, Ara, Fuc, Xyl, Man in the free state.

In the free state, the plants contain Frc $-0.27 \mathrm{mg} / \mathrm{g}$ and $0.31 \mathrm{mg} / \mathrm{g}$, disaccharide $\mathrm{Sac}-15.53$ and $6.13 \mathrm{mg} / \mathrm{g}$, almost not banded pinitol -16.76 and $17.60 \mathrm{mg} / \mathrm{g}$ and halfbanded myo-inositol -0.63 and $0.59 \mathrm{mg} / \mathrm{g}$ in $\mathrm{HG}$ and $\mathrm{HP}$ respectively.

Pinitol (D-3-O-methyl-chiro-inositol) and myo-inisitol have significant hypoglycemic and anti-diabetic action. Pinitol is being used as a nutritional suplement. They are the major solute in members of the Pine and Bean Familly. For example in soybean roots, these sugars are detected in the quantity of $1.9 \mathrm{mg} / \mathrm{g}$ and in Maritime pine $-2.0 \mathrm{mg} / \mathrm{g}$ $[5,8]$. The high content of pinitol in HG and HP proven their using in traditional medicine against diabetes.

In free and bounded states in the studied objects the stereoisomer of sorbitol - D-mannitol was detected. It's content was calculated as 1.60 and $1.42 \mathrm{mg} / \mathrm{g}$ in a free state and 0.19 and $0.28 \mathrm{mg} / \mathrm{g}$ after hydrolysis in HG and HP, respectively. The monosaccharide well-known for its osmotic,diuretic, vasodilatory properties, which have an impact on the reduction of intestinal sugar absorption [7].

\section{CONCLUSIONS}

We established for the first time, the carbohydrates composition after a complete hydrolysis and in a free state for two herbs: Herniaria glabra L. and Herniaria polygama J.Gay. The obtained results make these plant materials perspective for the future medical application against diabetes and metabolic disorders. However, in the future studies metabolomic and pharmacological investigations should be undertaken to better assess their potential.

\section{REFERENCES}

1. Akulshina E.V. and Darmohray V.N., Results development of techniques chromatospectrometrical definitions of herniarin and umbelliferone in the herb of Herniaria polygama. J. Rossiyskij mediko-biologicheskij vestnik imeni akademika I.P. Pawvlova, 3, 147, 2010.

2. Chen Y. et al, Analysis of the monosaccharide composition of purified polysaccharides in Ganoderma atrum by capillary gas chromatography. J. Phytochem Anal., 20 (60), 503, 2009.

3. Ecoflora of Ukraine. Volume 3. Editor in chief Ya Didukh, 2002, Phytosociocentre, Kiev p.495.

4. Freiler M. et al, New triterpene saponins from Herniaria glabra. J. Helvetica chimica acta, 79, 385, 1996.

5. Garland S. et al, Application of derivatization gas cromatography/ mass spectrometry for the identification and quantitation of Pinitol in plant roots. J. Analytical Letters, 42, 2096, 2009.

6. Maleš Ž. et al, Investigation of flavonoids, phenolic acids and amino acids of smooth rupturewort - Herniaria glabra L. J. Farmaceutski glasnik, 69 (11), 2013.

7. Muizelaar J.P. et al, Mannitol causes compensatory cerebral vasoconstriction and vasodilation in response to blood viscosity changes. J. Neurosurg, 59, 822, 1983.

8. Nguyen A. and Lamant A., Pinitol and Myo-inositol accumulation in water-stressed seedlings of seedlings of Maritime pine. J. Phytochemtstry, 27 (11), 3423, 1988. 